\title{
SALA REVOLUTI: CONCEPÇÃO E DESENVOLVIMENTO DE UM MODELO DE "SALA DE AULA DO FUTURO"
}

\author{
CRONEMBERGER, E; LAGE, D; GUIGON, G. \& SOBREIRA, H. G.
}

\section{Resumo}

As questões da "escola moderna", da "aula moderna" e das "salas de aula do futuro" são tão antigas quanto à própria reconstrução da educação em seu modelo escolar contemporâneo. Há uma transformação no tecido social contemporâneo que coloca em xeque os rumos da escola, para além das formas como vem sendo analisados e criticados. Trata-se da progressiva informatização do cotidiano que transcende a questão da posse de equipamento e sugere que em menos tempo do que se imagina o "direito à conexão" será importante questão social. Este artigo apresenta o estágio de desenvolvimento das pesquisas, iniciadas em 2007, sobre a Sala de Aula do Futuro realizadas pelo Programa de Pós-Graduação em Educação, Cultura e Comunicação (UERJ/FEBF) e pela Habto Design (empresa incubada pela UERJ/ESDI) que resultaram na Sala Revoluti. A situação-problema básica que gerou esse trabalho foi a percepção de um paradoxo entre as teorias e práticas de inovação que são próprias aos campos da Educação e da Informática. Em síntese, ambas inovações pareciam atuar em sentidos opostos nas salas de aula, o que reduz a informatização das escolas à construção de laboratórios de informática. A pesquisa abandonou o conceito de tecnofobia como explicação das dificuldades da informatização do cotidiano da aula e por meio do conceito de tecno-lag chegou à proposta de um novo mobiliário escolar (sistema de mesas articuladas) que contribuísse para a superação do paradoxo. $\mathrm{O}$ artigo, além de apresentar os elementos conceituais que geraram a proposta, debate ainda o papel desse novo design de sala de aula como viabilizador de um ambiente de educação em que ela se realize, simultaneamente, nos campos "do real" e "do virtual" e estimula pesquisas a respeito de uma Pedagogia que, para além do tradicional "download", possibilite o aprendizado pela interação e pelo "upload".

Palavras chave: educação, informática, design, sala de aula do futuro. 


\section{Abstract \\ The REVOLUTI CLASSROOM: DESIGN AND E DEVELOPEMMENT OF A MODEL FOR "THE CLASSROOM OF THE FUTURE"}

The issues of "modern school", the "modern class" and the "classroom of the future" are as old as the actual reconstruction of education in his school model. There is a transformation in the contemporary social network that calls into question the school, in addition to the forms as it has been analyzed and criticized. This is the progressive inormatization of everyday life which transcends the question of ownership of equipment and suggests that in less time than we think "connection rights" will be important social issue. This article presents the developmental stage of research, begun in 2007 on the Classroom of the Future carried out by the Post-Graduate Program Educação, Cultura e Comunicação (UERJ / FEBF) and Habto Design (company incubated at UERJ / ESDI ) which resulted in Revoluti Room. The basic problem that generated this work was the perception of a paradox between theory and practice of innovation that are specific to the fields of Education and Informatics. In summary, both innovations seemed to work in opposite directions in the classroom, which reduces the inormatization of schools to the construction of instructional labs. The research replace the notion of technophobia as an explanation of the difficulties of inormatization of classrooms for the concept of techno-lag and has proposed new school furniture (tables articulated system) which would help overcome the paradox. The article, besides presenting the conceptual elements that led to the proposal, debate still the role of the new design of the classroom as a facilitator of learning environment which takes place simultaneously in the "the real" and "virtual" and encourages research about a pedagogy that, in addition to the traditional "download", enables learning by interaction and "upload".

Keywords: education, information technology, design, classroom of the future 


\section{1 - Introdução}

As questões da "escola moderna", da "aula moderna" e das "salas de aula do futuro" são tão antigas quanto à própria reconstrução da educação em seu modelo escolar contemporâneo. Esse caráter utópico e prático orientou a intervenção de diversos professores e estudantes e indica o quanto a escola sempre foi necessária e, ao mesmo tempo, insatisfatória para os habitantes de seus variados espaços.

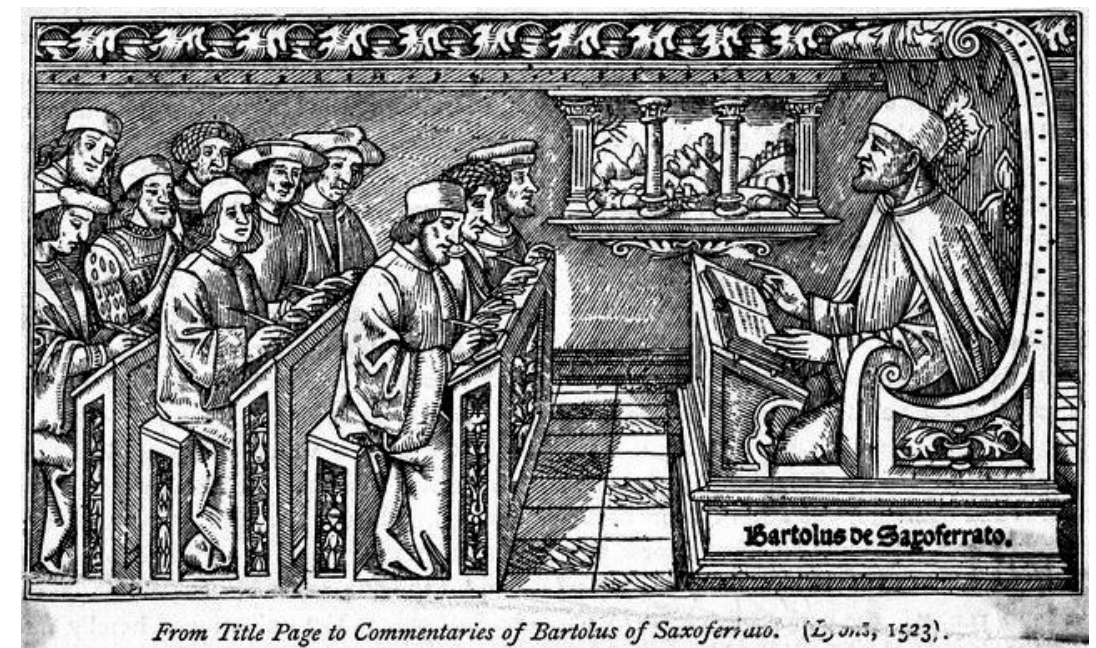

Sala de aula medieval

Consideramos desnecessário relatar todos os movimentos de transformação e de conservação que acompanham a história da educação propriamente escolar. Inclusive porque, além de variados e multifacetados, esses relatos apresentam, via de regra, graves denuncias dos aspectos de conservação e são extremamente apologéticos em relação à necessidade de transformação. A sequência de fotos abaixo é um bom exemplo dessas duas perspectivas.

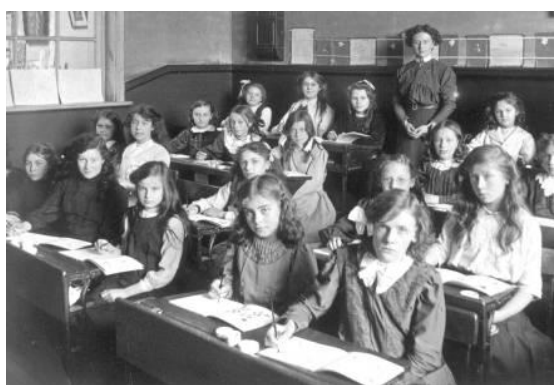

Londres 1905

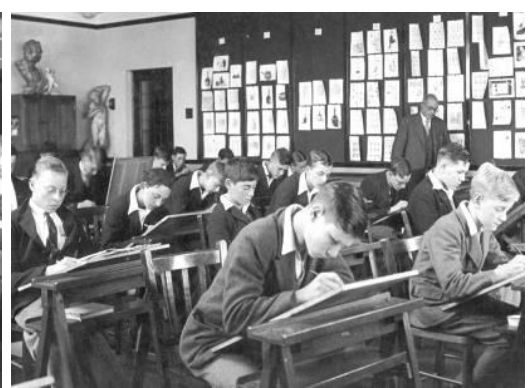

Londres 1950

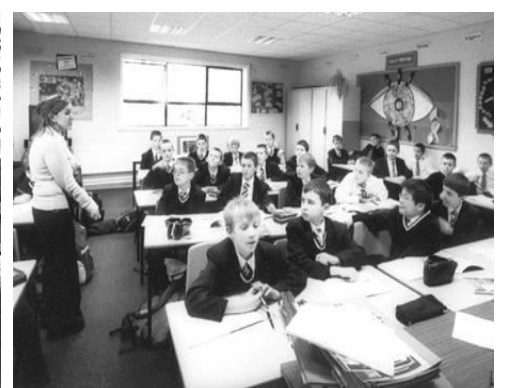

Londres 2004

Há, porém, uma transformação no tecido social contemporâneo que coloca em xeque os rumos da escola, para além das formas como vem sendo analisados e 
criticados. Trata-se da progressiva informatização do cotidiano que transcende a questão da posse de equipamento (que são tantos e tão diferentes) e tendencialmente sugere que em menos tempo do que se imagina o "direito à conexão" será tão importante como questão social quanto o são, por exemplo, os direitos à água e esgoto e à energia elétrica. Temos, a custos cada vez menores, telefones celulares que possuem processadores e memória mais potentes do que os primeiros Personal Computers do final da década de 1970 e começo da de 1980. Jovens estudantes de todas as faixas de renda chegam às escolas com habilidades de conexão maiores do que a de seus professores. As iniciativas de criação de equipamentos de informática para distribuição entre escolares são fortes e extremamente bem recebidas pela população e pelos governos.

É nesse campo que se inserem as pesquisas, iniciadas em 2007, sobre a Sala de Aula do Futuro realizadas pelo Programa de Pós-Graduação em Educação, Cultura e Comunicação (UERJ/FEBF) e pela Habto Design (empresa incubada pela UERJ/ESDI) que resultaram na Sala Revoluti. O objetivo desse artigo é consolidar e apresentar os resultados dessa pesquisa para que novos avanços possam ser realizados.

\section{2 - A Sala Revoluti: conceito, realização e método}

A SALA (ou SISTEMA) REVOLUTI é resultado de um trabalho de dois anos de pesquisa e de cooperação técnica entre duas Unidades da UERJ, a Faculdade de Educação da Baixada Fluminense (por meio de seu Programa de Pós-Graduação em Educação, Cultura e Comunicação) e a Escola Superior de Desenho Industrial (por meio da Habto Design, empresa incubada).

A situação-problema básica que gerou esse trabalho foi a percepção de um paradoxo sutil entre as teorias e práticas de inovação que são próprias aos campos da Educação e da Informática. O desenvolvimento dos estudos pedagógicos aponta que os modelos de aula descentralizados, participativos e interativos conduzem a processos e resultados de ensinar e de aprender mais agradáveis e eficientes. $\mathrm{O}$ desenvolvimento do campo da informática (e de redes) também se afirma como modos de interação descentralizados e participativos.

No entanto, o computador e a internet, se já consistem em suporte para os processos de ensinar e aprender do ponto de vista de seu uso individual, quando 
introduzidos em salas de aula operam em contradição com os avanços pedagógicos rumo à descentralização do processo de ensinar e aprender. Os atuais modelos de equipamento escolar e de equipamento de informática criam obstáculos físicos aos modelos de pedagogia que possuem a interação como seu fundamento.

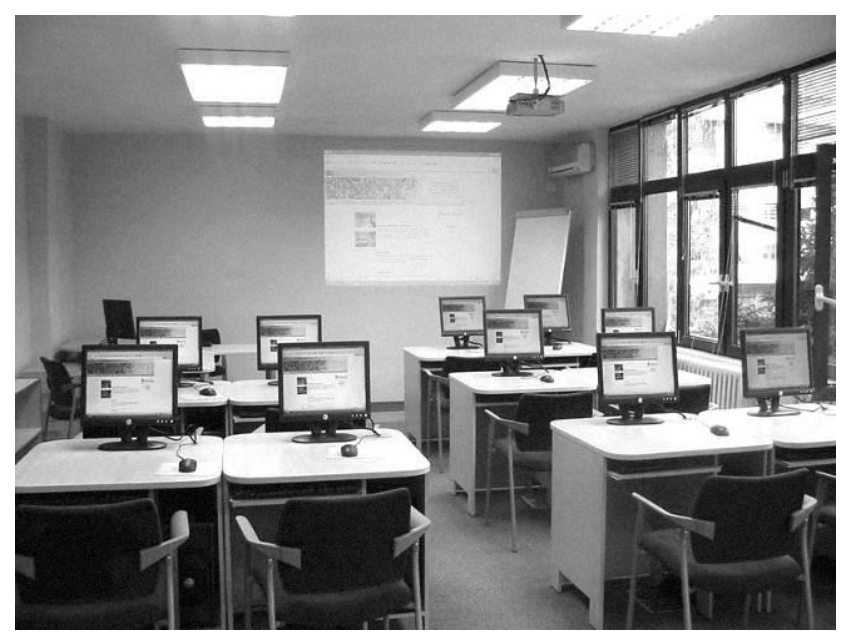

Modelo convencional de introdução de computadores na sala de aula

Desta forma, a informática e a internet são utilizadas ou bem como equipamento de uso individual por professores e estudantes fora do espaço escolar ou bem como laboratórios de informática para uso eventual. Consideramos que esse paradoxo gera, na verdade, uma subutilização do potencial desse equipamento. Dessa subutilização resulta que a distância entre os desejos do que "a aula deveria ser" e a realidade do que ela "continua sendo" torna-se cada vez maior.

Há dois conceitos do campo da internet que podem ser utilizados para descrever de forma mais apropriada a evolução desse paradoxo. A interatividade inicial na internet se concentrou na ampliação da da "capacidade de download" (baixar programas e conteúdos por meio da conexão). A inovação permitida pela disseminação do acesso por meio de conexões do tipo banda larga (em especial as com velocidade superior $1 \mathrm{MBps}$ ) introduz a perspectiva da interatividade por meio do "upload" 1 (carregamento, pelo usuário comum, de conteúdo na rede mundial). As perspectivas de inovação pedagógica desenvolvidas ao longo do séc. $X X$ podem ser metaforizadas como "educação via upload", pois implicam processos educativos em que o estudante deixa de ser o mero receptor de conteúdo e passa, junto com seus

1 - A rigor, o simples ato de enviar uma mensagem eletrônica (e-mail) já consiste em exercício de "upload”, a conexão em banda larga "ampla" permite que conteúdos mais complexos possam ser "carregados" na rede mundial. 
professores orientadores, a também serem formuladores de conhecimento. Porém, os atuais processos de informatização escolar operam prioritariamente como "educação via download", em tempos em que as demandas dos jovens usuários estão concentradas também nos processos de "interação via upload", que já exercitam fora do ambiente escolar.

Nossa investigação tinha como eixo central o desenvolvimento de um equipamento escolar que, a custos baixos de instalação e manutenção, conjugasse os dois potenciais de inovação (o pedagógico e o da informática) permitindo que todas as aulas fossem realizadas, simultaneamente, em ambientes interativos "real" $e$ "virtual", combinando em seu cotidiano as possibilidades de download e upload. Esse novo modelo de equipamento deveria ser de utilização fácil e segura para as pessoas e para os equipamentos. Na pesquisa básica que realizamos descobrimos que nossas questões estavam sendo estudadas também por diversos grupos de pesquisa (em Universidade e Empresas) sob o título de "sala de aula do futuro".

Desde o surgimento do primeiro computador pessoal nos anos 70, passando pela consolidação da internet como meio de comunicação, temos hoje uma grande mudança na forma de adquirir e compartilhar informação. Nesse contexto, a Educação sempre foi considerada como uma das áreas que seriam mais afetadas por essas mudanças. De certa forma já foi. Mas talvez tanto pelos custos iniciais desses equipamentos quanto pelo seu rápido desenvolvimento (que não podem ser incluídos/analisados por meio da categoria "obsolescência planejada"), mesmo os sistemas nacionais de Educação que se caracterizam pela oferta dos tradicionais equipamentos suplementares para seus escolares (livros didáticos, transporte e alimentação, principalmente) ainda não incluíram em seus orçamentos os custos de informatização escolar para todos os estudantes (sendo exceção as pesquisas sobre - OLPC ou UCA - um computador para cada aluno)

De certa forma, no sentido privado ou pessoal, a "informática em rede" já está presente no cotidiano de docentes e discentes da Educação Básica e Superior nos países mais desenvolvidos econômica e socialmente. Mas no sentido social ou público, o uso do computador e suas tecnologias como ferramenta educacional é incipiente nesses países e praticamente ausente nos demais, mesmo entre aqueles que, como o Brasil, possuem subsistemas difere nciados de atendimento escolar de 
acordo com o nível sócio-econômico de suas famílias. A queda dos custos de aquisição dos equipamentos provocou pequeno efeito na informatização interativa da sala de aula. Esta situação sugere a existência de outras barreiras à essa introdução.

Sendo assim, partimos do pressuposto de que o ambiente da sala de aula permaneceu inalterado e que, para acompanhar a dinâmica existente "no mundo da informática", ele precisava ser re-estruturado para possibilitar a plena utilização destes novos recursos. Essa re-estruturação nos apresentou como complexa, pois precisava resolver a contradição física que impede a articulação positiva entre os mais novos modelos educacionais e os recentes (e em processo de desenvolvimento acelerado e contínuo) modelos de "informática em rede".

Essa articulação deveria levar em consideração a necessidade e os problemas de o professor deixar de ser a única fonte de conhecimento e passar a funcionar como um guia, estimulando e orientando os alunos na busca e análise das informações disponíveis nas mais diferentes mídias. No caso dos estudantes, estes passariam de meros espectadores passivos a solucionadores de problemas práticos, capazes de pesquisar, criticar e debater temas relacionados aos conteúdos educativos. Nessa abordagem, o computador e a internet seriam ferramentas essenciais para a educação, da mesma forma como ocorre no dia-a-dia das pessoas e não mero recurso didático-pedagógico de apoio às atividades de ensinar e de aprender.

Para atender às necessidades descritas, uma nova dinâmica na sala de aula se faz necessária. Nela, os alunos que atualmente ficam isolados em filas de carteiras individuais e passariam a realizar mais atividades em grupo, enquanto o professor, que hoje permanece estático a maior parte do tempo, deveria interagir mais e circular entre os alunos verificando $o$ andamento das atividades.

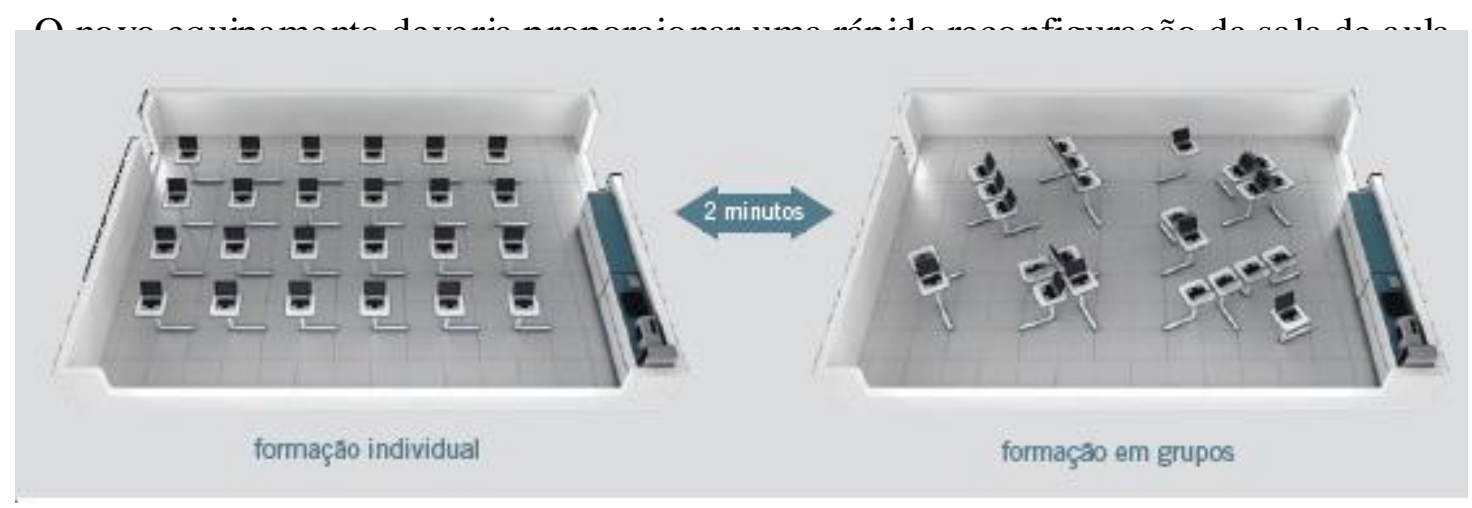


O mobiliário para salas de aula está muito desatualizado, pois segue uma estrutura de aula que é usada desde a idade média, com os alunos sentados enfileirados e o professor parado na frente, como uma figura centralizadora do conhecimento. A difusão da informática e a facilidade de acesso à informação tornaram mais urgente a necessidade de revisar o espaço onde se dá a formação dos alunos. É em cima dessa premissa que as propostas de um novo sistema de ensino, mais dinâmico e flexível, foram estudadas.

O primeiro conceito que desenvolvemos tratava de resolver o problema da introdução do computador/estação de trabalho que não impedisse o contato físico/visual entre docentes e discentes e entre discentes entre si. Esta solução precisava incorporar também a possibilidade de "equipamento móvel" para que configurações alternativas de sala de aula pudessem ser exercitadas (conforme demonstrado nas fotos em seguida, do mesmo conjunto de sete estações da nossa "sala protótipo").
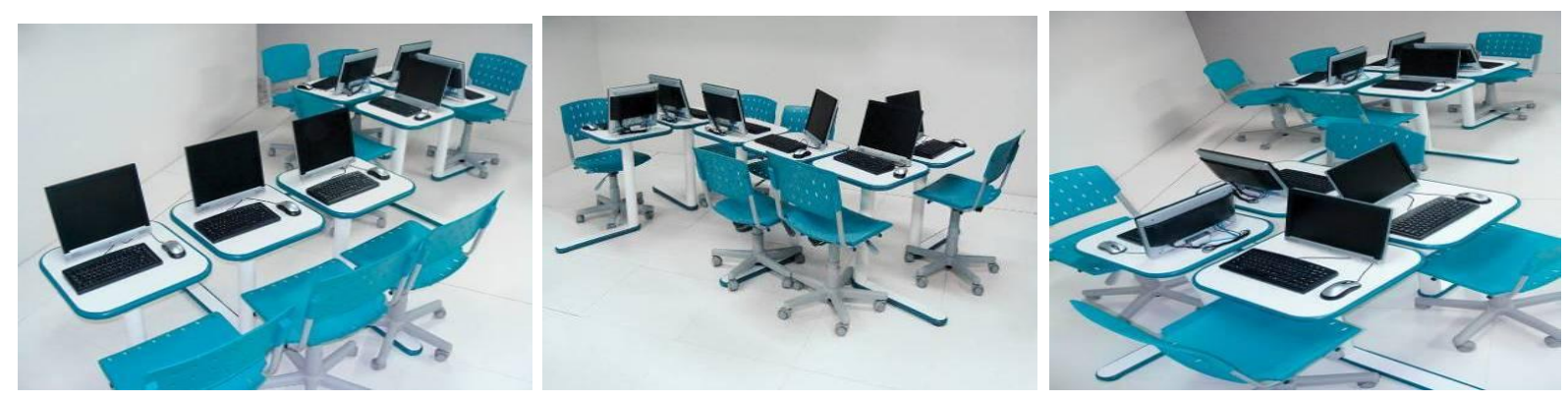

Três arranjos distintos do mesmo conjunto de mesas da Sala REVOLUTI (protótipo instalado na FEBF)

Sendo assim, o Sistema Revoluti se caracteriza como uma inovação tecnológica, pois consegue conciliar a inserção do computador na sala de aula com a dinâmica necessária para o funcionamento desse novo modelo educacional, criando um ambiente estimulante que proporciona uma melhor qualidade de ensino. Após um grande levantamento de similares feito no Brasil e no exterior e de comprovar a inexistência de propostas que dessem conta desses problemas, foi realizado o depósito de patente de invenção junto ao INPI (CRONEMBERGER; LAGE; GUIGON \& SOBRE IRA, 2009).

Os produtos encontrados atualmente no mercado, e até mesmo os protótipos e conceitos que estão sendo desenvolvidos no Brasil e no Mundo, não repensam o sistema de ensino a partir das mudanças provocadas pelo computador. Mantendo a 
estrutura ultrapassada das salas, os sistemas de informatização escolar que já existem não se beneficiam das vantagens de uso que essa ferramenta, cada vez mais presente na vida das pessoas, pode oferecer, seus efeitos se limitam à fascinação própria que novas tecnologias possuem quando introduzidas. A principal limitação que as formas atuais de informatização escolar ou educativa oferece é que ela responsabiliza os usuários (docentes, principalmente) pela sua subutilização. Os agentes da introdução acusam a escola de "tecnofobia" e os docentes respondem às inciativas com elevadas, mas compreensíveis, demandas de qualificação prévia no uso dos equipamentos.

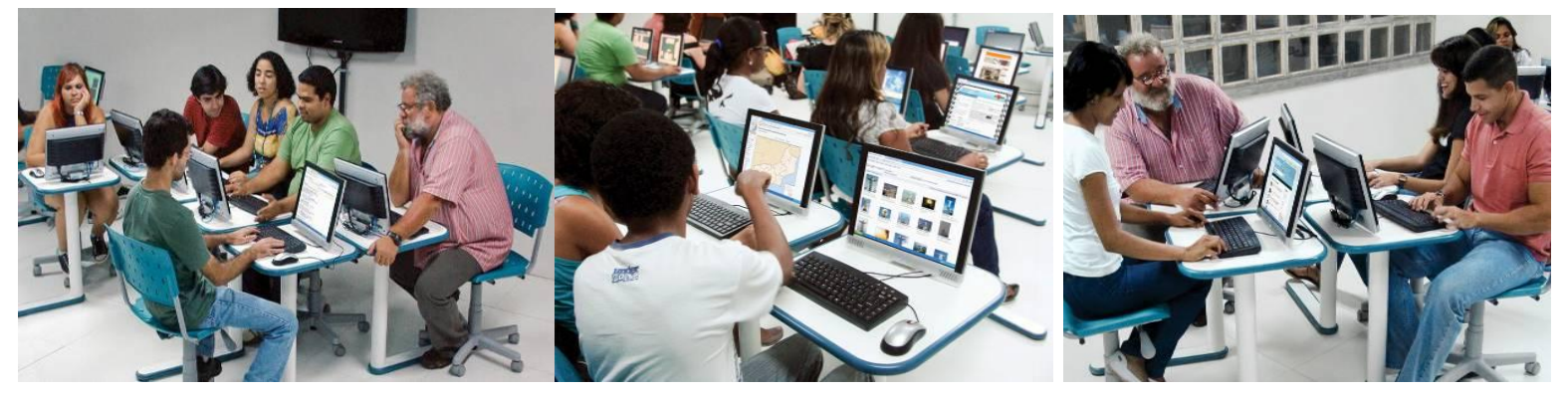

Primeiras experiências de uso didático da Sala Revoluti em que a interação física entre os usuários é ressaltada.

Isso explica a forma como esse equipamento vem sendo introduzido nas escolas. Segundo dados do MEC, entre os anos 2000 e 2006, praticamente dobrou o número de escolas de ensino fundamental que possuíam laboratórios de informática. Mas não há relatos sobre processos já em andamento do uso da informática no cotidiano da aula presencial. Por outro lado, há um fenômeno interessante nas escolas privadas (em especial as de custo mensal acima de $R \$ 500,00$ ), se até 2001-2002 a existência de laboratórios de informática e de "cursos de informática" eram fator de vantagem no mercado, hoje não cumprem mais essa função, tendo em vista que sua clientela é mais ágil em renovar os equipamentos de uso privado e passaram a ser fonte de custos sem conduzir a benefícios.

Em 1995 De KERCKHOVE postulava o tecno-lag ao constatar que entre o seu primeiro contato com uma máquina de fax (1972) e a sua disseminação social (por volta de 1985) passou-se um tempo aparentemente inexplicável tendo em vista as vantagens do equipamento. Esse fenômeno não seria eventual (já tinha acontecido com a televisão) e o autor apresenta, para o caso do fax, uma explicação em "duas metades" A primeira metade é a infra-estrutura tecnológica já existente. Assim, por 
mais que os japoneses estivessem interessados em encontrar formas de transmitir seus documentos redigidos no seu difícil sistema de escrita, os sistemas telefônicos internacionais não estavam prontos para suportar essa carga. Mas a segunda é capital, pois "a melhor e mais útil tecnologia do mundo não pode impor-se a um público não preparado"(1997: 31).

De KERCKHOVE porém alerta que superado o tecno-lag e mantendo-se o novo aparato na esfera de consumo pode-se cair na obsessão fetichista em relação ao novo aparato. Entre a mera aquisição por força da propaganda sobre a novidade e a posse como padrão psicológico de identificação narcísica com o poder "dos novos brinquedos", ele prefere interpretar essa segunda fase como derivada da percepção que os aparelhos são adquiridos não porque se deseja que cumpram todas as funções possíveis, mas para que nos livrássemos da sensação de limitação e de inadequação caso não os possuíssemos.

No entanto, se o conceito de tecno-lag contribui para explicar os motivos de nas escolas a informática se limitar a esse "cenário de laboratórios", apontam para um outro problema (ou característica) no campo de "subutilização". As atividades com a mediação da tecnologia produzem um efeito "didático" (facilitador do processo de aprendizagem) na esfera de consumo (download) quando o seu uso escolar é eventual ou seu uso educativo é privado. Perdem-se os aspectos em que essas Tecnologias da Inovação ${ }^{2}$ operam no estímulo para que seus participantes inovem tanto por meio da sugestão de novos usos para antigos equipamentos e programas (softwares), quanto por meio de introdução de novas propostas que até então estavam no nível do "ouvi falar" ou "li em algum lugar que isso pode ser feito de tal o qual maneira". Em outras palavras, perde-se boa parte do potencial na esfera da produção, do "eu também posso fazer" (upload). Ao abandonarmos a busca de solução do paradoxo com a abordagem derivada da categoria "tecnofobia" e introduzirmos a busca de soluções que reduzissem o tecno-lag, estabelecemos um novo campo de estudos e intervenção.

- Desde fins da década de 1980 (lá se vão quase 20 anos) surgiu o debate sobre as novas tecnologias de informação e comunicação (e suas variantes). Nossos trabalhos e estudos apontam para duas questões. Primeiro, elas não são mais tão novas ( como adjetivo) e segundo, e mais importante, uma das suas características é serem marcadas pelo binômio hardw are e sof tware que se retroalimentam de forma conjugada tanto nos processos de sua simples utilização quanto nas demandas de desenvolvimento que sugerem aos usuários. Optamos aqui por chamá-las de tecnologias da inovação, pois não só inovam, mas exigem a inovação.
} 
Entre os estudos realizados sobre essa contradição, encontramos em BLIKSTEIN \& ZUFFO (2009) um dos que mais se aproximava/explicava àquilo que até então conferíamos o nome de efeito demonstração, característica presente quando há uso em larga escala e cotidiana da informática interativa. Os autores possuem como ponto de partida que:

(...) não basta introduzir tecnologias - é fundamental pensar em como elas são disponibilizadas, como seu uso pode efetivamente desafiar as estruturas existentes em vez de reforçá-las.

Propõem um "exercício de imaginação" em que sugerem os atos dos senhores feudais caso extraterrestres deixassem, na ldade Média, um grande carregamento de computadores portáteis com uma rede sem fio semelhante à Internet. Com o feudo "cheio" de computadores os poderes políticos rapidamente iriam decidir quem é que poderia, ou não, ter acesso às máquinas e os poderes religiosos criariam os códigos de conduta para que fossem proibidos os usos heréticos ${ }^{3}$. Advertem que tal situação é homóloga ao que acontecia nos espaços de tecnologia existentes nas escolas à época da pesquisa (2001) e sugerem três causas para as proibições:

(...) a preponderância da mentalidade de muitos dos tecnologistas (...) acostumados aos regulamentos e proibições do ambiente corporativo. (...) a preponderância da mentalidade de muitos dos administradores escolares, acostumados aos regulamentos e proibições do ambiente escolares. (...) [e] o modelo de disponibilização de equipamentos e tecnologias, em que escolas e professores são meros consumidores desses caros artefatos tecnológicos (...). Portanto, a forma de disponibilização e as mensagens ocultas no uso das novas tecnologias são tão importantes como a decisão de usá-las.

Assim como no cenário de imaginação, o uso revolucionário das máquinas seria inventado às escondidas. Nas escolas atuais esse equipamento seria utilizado de forma herética e secreta fora dos estritos regulamentos de conduta e comportamento ${ }^{4}$.

\footnotetext{
3 É interessante apontar que o texto foi redigido a partir de uma Dissertação de Mestrado defendida em 2001, portanto, antes da revolução da "banda larga" e da criação da Web 2.0, em um momento que a preocupação ainda era em relação a uma possível "exclusão digital" que os tempos não confirmaram, se esse conceito se limitar a apontar a falta de máquinas e/ou de acesso à internet. Infelizmente tudo indica que o "exercício de imaginação" se configurou em profecia, se levarmos em consideração as práticas usuais que orientam os Laboratórios de Informática de Universidades Públicas ou Privadas.

No Estado do Rio de Janeiro foi sancionada em abril de 2009 uma lei que proíbe o uso de aparelhos celulares em sala de aula $(G 1,2009)$ a despeito da investigação acadêmica já estar se detendo sobre a utilização desses aparelhos em sala de aula, como em MONTEIRO (2009) ou a respeito de seu impacto na reconfiguração das subjetividades da juventude, como em LIMA (2006). É interessante notar que não há "nova tecnologia" mais disponível ao conjunto da população do que o
} 
A diferença apontada por BLIKSTEIN \& ZUFFO (2009) entre essa nova aparelhagem e as demais inovações tecnológicas próprias dos últimos dois ou três séculos da sociedade é que se não há como fabricar um carro no quintal, com martelos e pedaços de metal [é] preciso industrializá-lo, produzi-lo em série, com as tecnologias digitais podemos ser, ao mesmo tempo, produtores e consumidores. Os seus baixos custos permitem a sua constante reinvenção (quase que produção em "fundo de quintal") tanto no que toca a novos usos de "periféricos antigos", quanto no que se refere à impossibilidade de controle do uso das "plataformas" da internet (blogs, páginas de relacionamento, páginas de disponibilização de conteúdo etc.) e até mesmo criação de novos equipamentos e plataformas de internet ${ }^{5}$.

(...) as mídias digitais oferecem infinito espaço para experimentações em diferentes níveis de realidade, seja programando o computador, editando filmes, fazendo robótica, construindo modelos computacionais ou elaborando sites na internet, com uma equação de custo fundamentalmente diferente. Que fique claro: não estamos falando do custo do ponto de vista negocial, da distribuição de conteúdos a baixo preço. Falamos do aluno, daquele que quer aprender e que não deseja necessariamente a solução de mídias que minimize o custo da empresa de ensino eletrônico, mas que maximize o que ele pode aprender. (BLIKSTEIN \& ZUFFO, 2009)

Nossos estudos consistiram, portanto, na análise de mudanças de infraestrutura escolar que permitissem a introdução da informática em rede no cotidiano da sala de aula. A falta de sistemas que viabilizem essa introdução congela todas iniciativas em um ponto equivocado, a suposição da tecnofobia nas escolas e, principalmente, entre os professores. Em outras palavras, é necessário superar o aspecto infraestrutural do tecno-lag para que os seus aspectos subjetivos pudessem ser tratados.

\section{3 - A estação de trabalho e as suas articulações}

Foi assim que com o objetivo de superar os empecilhos infraestruturais à informatização do cotidiano da aula e visando a dinamizar os processos de ensino levando professores e estudantes a serem produtores de sua aprendizagem é que

aparelho de telefone celular. Essa lei opera em sentido contrário do que sugerem os "nossos tempos". Se atualmente o telefone celular age em "prejuízo da aprendizagem", de acordo com os propositores da lei, talvez não haja campo mais instigante e proveitoso para se implantar uma educação mais integrada à modernidade tecnológica do que exatamente o potencial dos aparelhos celulares como instrumento pedagógico. Proibidos em sala de aula, os telefones e outros "gadgets" serão experimentados hereticamente como tal pelos estudantes.

5

Sendo que isto seria uma boa explicação para a redução do tecno-lag postulado por De Kerckhove. 
se chegou ao modelo de Sala de Aula do Futuro, doravante denominado Sala Revoluti ou simplesmente Revoluti.

A parte mais elementar da Revoluti é a estação de trabalho. Cada estação individual é composta por uma mesa giratória com o equipamento de informática integrado. $A$ mesa está fixada ao chão por um eixo descentralizado em relação do seu tampo. Sua rotação permite a formação de grupos de duas, três, quatro ou seis estudantes, alem das disposições em círculo, em ferradura, e diversas outras possibilidades. Uma série de características dessa mesa contribuem para a melhoria do seu uso e também do funcionamento da sala. Para aumentar a segurança dos usuários da sala e do equipamento nela instalado, sua estrutura permite passagem interna para os cabos de energia, reduzindo o risco de acidentes e o tampo da mesa possui borda de borracha para absorção de eventuais impactos. Para aumentar o conforto durante o uso, as cadeiras usadas possuem ajuste de altura, e o monitor, foi mantido em uma altura baixa para estimular a interação entre os alunos, possui ajuste de inclinação. A posição rebaixada do monitor permite que alunos e professores não percam o contato visual, tão importante para que se favoreça a interação entre eles.

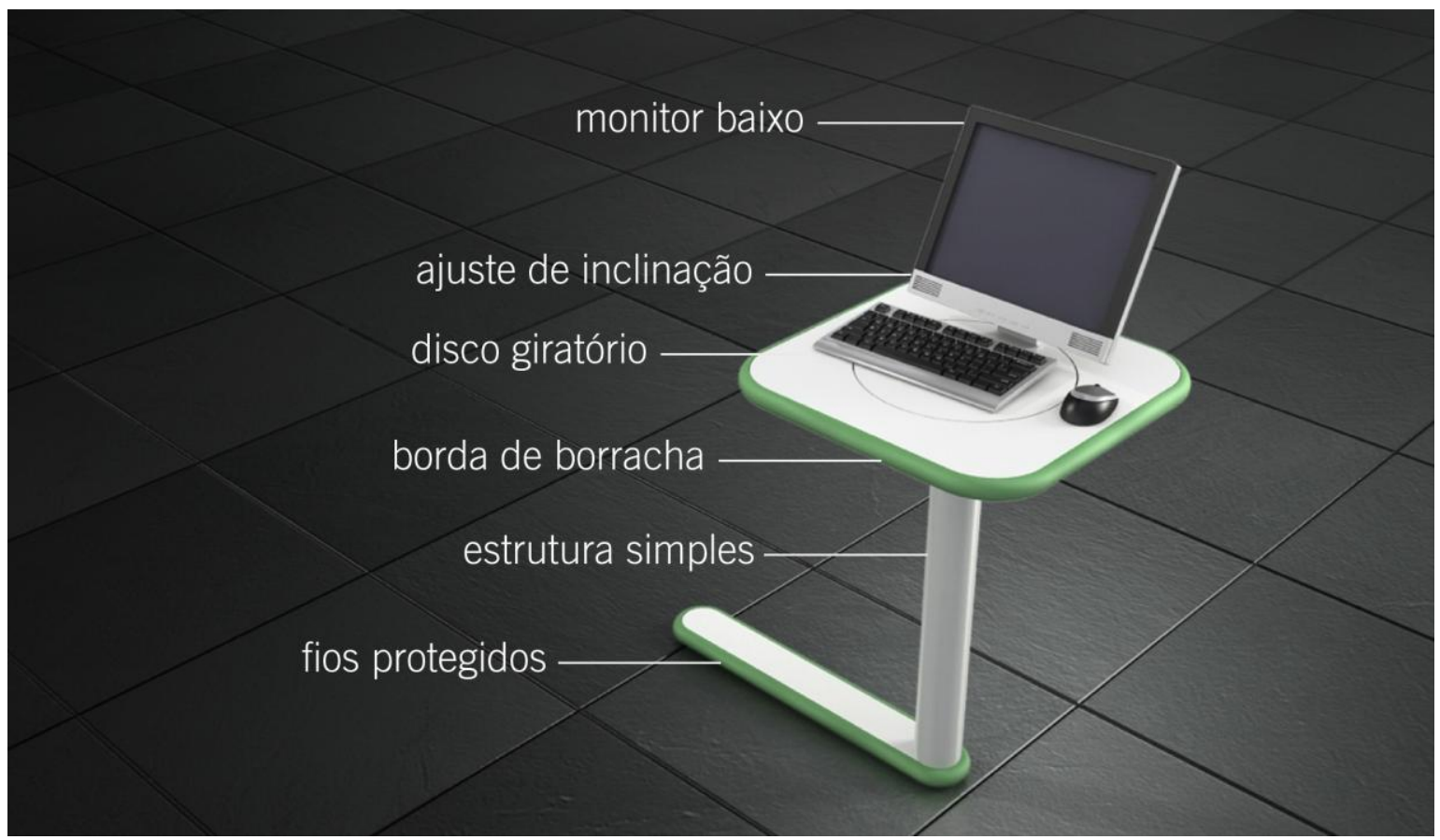

Principais elementos da Mesa Articulada

Apesar da importância da mesa como elemento central da Revoluti é a configuração das estações individuais na sala que potencializa o seu uso. A distância entre cada 
mesa deve ser precisa para garantir a maior quantidade de formações possível. Essa distância é garantida pelo uso de um piso elevado, que também reduz a necessidade de obras de adaptação da instalação elétrica e lógica, e possibilita maior facilidade e agilidade na implantação e manutenção da sala.

Deve-se dar destaque também ao equipamento de informática escolhido para a sala piloto Revoluti, o "thin client" ${ }^{6}$. Cada estação possui um monitor, teclado, mouse e um "thin client". Esse sistema possibilita que o processamento de dados de toda a sala seja realizado por apenas um servidor de alta performance. Como não é usada uma CPU para cada estação, há ganho de espaço, redução da energia utilizada pelas máquinas, redução do calor gerado e por consequência da energia utilizada na refrigeração da sala. Além do mais, essa opção é facilitadora da implantação de upgrades. Um dos principais problemas da informatização pública consiste exatamente na velocidade com que os equipamentos e os programas evoluem, atualmente em menos de dois anos se estabelece uma defasagem que exige substituição quase que total do sistema. Na Revoluti esses custos são reduzidos por se concentrarem apenas nas alterações realizadas no servidor. Além do mais, o servidor é a estação de trabalho do professor. Este é um aspecto importante, pois para o bem e para o mal possibilita ao professor o gerenciamento dos acessos à internet que são realizados pelos estudantes em suas estações.

A sala com mesas articuladas também comporta a instalação de outros tipos de equipamentos como laptops, que tem seu preço cada vez mais acessível. Assim, no caso de a solução para a informatização escolar passar pela distribuição de equipamentos como o OLPC, eles poderão ser conectados às mesas e os sistema manterá a flexibilidade didático-pedagógica que é um de seus conceitos principais.

A Revoluti também foi concebida prevendo a facilidade para a sua instalação. Essa é uma outra vantagem econômica, que foi possibilitada com a pela utilização do piso elevado como suporte para as mesas mesas individuais. Isso reduz as tarefas de infraestrutura para instalação a pequenos projetos de distribuição de rede elétrica e de lógica (excetuando-se o caso de rede sem fio) e obras de adaptação arquitetônica, para garantir o aproveitamento máximo do espaço e dimensionamento de refrigeração. 
CRONEMBERGER, LAGE \& GUIGON (2009) descreveram da seguinte forma a

\section{SALA REVOLUTI (sistema de mesas duplamente articuladas para suporte de} informatização do cotidiano pedagógico)

Nosso sistema de mobiliário foi desenvolvido com o foco em um novo modelo de educação que considera o professor como um guia do aprendizado e a informática como uma importante ferramenta para a formação dos estudantes. É composta por mesas individuais fixadas ao chão por um eixo descentralizado em relação ao seu tampo. As mesas podem girar em torno desse eixo e, ao fazê-lo, podem formar diferentes arranjos de sala, com grupos de 2, 3, 4 ou 6 pessoas, disposição em círculo, em ferradura, e diversas outras possibilidades, tornando a sala adaptável para diversos tipos de atividades. (...)

- Mobiliário/Mesas: É o elemento central do projeto, responsável pela geração de diferentes "layouts" de sala, de uma maneira rápida e prática. Tem estrutura giratória, confeccionada em aço, que permite a passagem dos cabos internamente. Seu tampo feito em MDF possui um disco giratório integrado com suporte "vesa" para monitor LCD. (...)

- Piso Elevado: É, na verdade, uma peça essencial para o funcionamento do sistema, pois permite que os cabos de energia e rede cheguem até as mesas sem atrapalhar a circulação do ambiente, além de possuir o eixo que permite a rotação da mesa.

- Projeto de Adaptação: Para implantação da sala, será necessário um projeto de adaptação às condições arquitetônicas de cada instituição, número de alunos por sala, sistema de hardware adotado, etc. (...)

- Instalação: Será necessária uma pequena obra para implantar o sistema, instalar o piso elevado, levar o cabeamento do hardware até as mesas e instalar os equipamentos de informática. (...)

- Hardware: as mesas foram desenvolvidas para que pudessem receber equipamentos de informática, como laptops ou "thin-clients", compostos por monitores $L C D$, teclado e mouse. (...)

- Software: (...) esta nova sala só funciona plenamente com uma metodologia de ensino própria, que certamente compreenderia ferramentas digitais (softwares). Nesse sentido, é muito interessante a parceria com a FEBF, onde será instalada a sala-piloto, pois essa será testada por uma turma de mestrado em educação, que poderá desenvolver o modelo de aula, e identificar as necessidades em termos de ferramentas digitais. Este desenvolvimento será feito em parceria com uma empresa de softwares, e poderá ser viabilizado por editais que contemplem inovações em tecnologia da informação.

- Treinamento: Visa garantir que os professores que utilizarão a sala aproveitem ao máximo as possibilidades do sistema. O professor deverá ser capaz de definir os melhores arranjos de acordo com o conteúdo que será estudado, estimular a interação entre os alunos, guiar os estudos e pesquisas, etc. Esse serviço será realizado em parceria com o corpo docente e discente da FEBF, que irá desenvolver as primeiras 
metodologias para esse modelo de sala de aula. O treinamento também será voltado para a utilização dos softwares específicos da sala.

A sala protótipo foi inaugurada na FEBF no dia 10 de setembro de 2009 e as pesquisas sobre o seu funcionamento já começaram. A necessidade de ampliar o número de salas e de pesquisadores e pesquisas desse modelo na UERJ partem da constatação que tendo em vista o número de grupos de pesquisa que investigam modelos de "salas de aula do futuro" em todo o mundo, em breve mais modelos tão interessantes e de fácil implantação surgirão no cenário da educação e da informática. As pesquisas realizadas durante o processo de confecção da Revoluti indicam a possibilidade de em menos de duas décadas todas salas de aula do mundo se utilizarão de algum dos modelos em desenvolvimento.

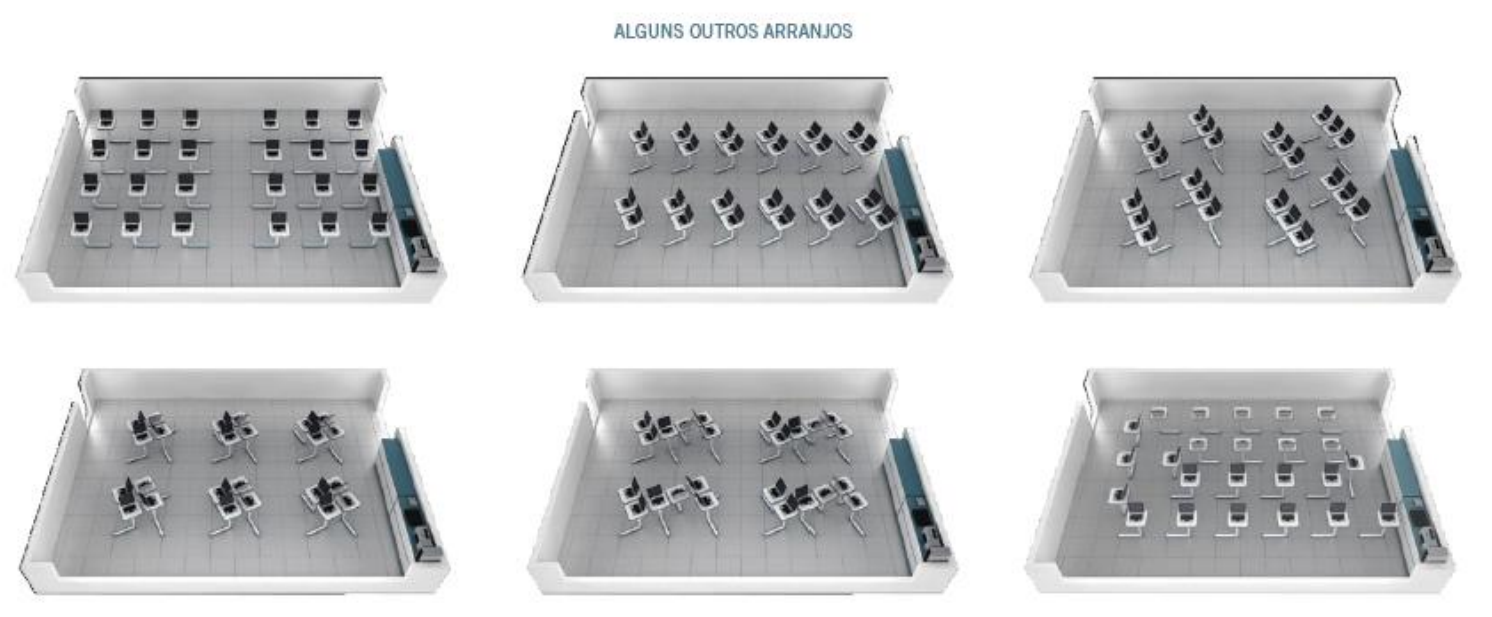

Seis disposições alternativas da Sala Revoluti

Nossas pesquisas indicaram que a Revoluti é um dos modelos mais avançados de sala de aula do futuro, mas esse pioneirismo pode ser superado caso as pesquisas sobre sua utilização não avancem. A continuação de nossos trabalhos se dará em duas frentes, a que conjuga investigação de hardwares alternativos (outros sistemas de estação de trabalho, introdução de monitores "touchscreen" etc) e evolução do desenho industrial que se desenvolve prioritariamente na Habto Design e a que investiga os modos e os efeitos de seu uso no cotidiano escolar, sob a responsabilidade principal da FEBF. A implantação de mais salas e a incorporação de mais pesquisadores das áreas de Educação e de Comunicação viabilizará a introdução da UERJ de forma privilegiada na pesquisa sobre os modelos de ensinar e de aprender que poderão ser utilizados na plataforma Revoluti ou nas demais em 
desenvolvimento ${ }^{7}$.

\section{4 - Análise de outros modelos de Sala de Aula do Futuro}

Nenhuma das propostas existentes no Brasil para inclusão da informática na sala de aula se consolidou como solução integral para as questões envolvidas nessa mudança de paradigma. Alguns exemplos são a Sala do Futuro da USP, a mesa Lap Tupniquim e a Carteira Informatizada da Oppitz.

O projeto de Sala do Futuro da USP, realizado na década de 90, ficou restrito ao campo da pesquisa acadêmica. Uma sala foi realizada e documentada usando o formato de ferradura como base para a disposição das mesas, modelo que parecia mais adequado à época.

A mesa Lap Tup-Niquim (ERENO, 2009) é uma carteira escolar com tampo de vidro com uma tela acoplada. O tempo pode ser inclinado para ser usado na posição horizontal, para escrita em cadernos e leitura de livros, ou na posição vertical, para uso do computador e da tela de toque. Esse movimento revela também o teclado e mouse, que ficam guardados sob o tampo. A mesa já está em fase de testes e foi instaladas em algumas salas de aula da rede municipal de ensino da cidade de Serrana, no estado de São Paulo. Cinco salas de aula do município foram equipadas com a mesa, e após o período de avaliação, a Prefeitura pretende estender o projeto para as 15 salas do município, mostrando que está em busca de uma solução viável que melhore a qualidade do ensino.

Os principais pontos fortes da Lap Tup-Niquin são o preço, a possibilidade de uso como mesa tradicional ou como tela, o fato de estar em uma etapa avançada do seu desenvolvimento, e o pequeno grau de alteração que proporciona na estrutura da sala de aula. Esta última característica, no entanto, também pode ser considerada seu maior ponto fraco, já que mantendo a estrutura da sala tradicional, são mantidas algumas das questões mais criticadas em nossa investigação: o isolamento entre os alunos, o distanciamento do professor e a rigidez da estrutura da sala. Nesse sentido, isola ainda mais os alunos, já que os tampos levantados para uso da tela criam verdadeiras barreiras físicas para o contato visual entre os alunos e o

\footnotetext{
$7 \quad$ Neste sentido foi apresentado (e aprovado pela FAPERJ) projeto de pesquisa sobre os modelos de Educação e de comunicação a serem utilizados em salas de aula completamente informatizadas. Serão instaladas em 2010 mais quatro salas Revoluti na UERJ (no Instituto de Aplicação, na Faculdade de Comunicação e na Faculdade de Educação da Baixada Fluminense) que serão campo para estudos realizados por um grupo de vinte e seis pesquisadores (SOBREIRA, 2009)
} 
professor.

A Cadeira Informatizada da Opptiz (OPPITZ, 2009) é a mais avançada no que diz respeito à comercialização. A Oppitz Soluções Tecnológicas foi fundada em 2001 e faz parte do Grupo Cequipel de fabricação de mobiliário corporativo e escolar. 0 grupo Cequipel foi fundado em 1983 e possui ampla experiência na produção e comercialização de mobiliário, além de um enorme parque industrial, com fábricas em São José dos Pinhais (PR), Biguaçu (SC) e Aracaju (SE). Neste mercado, seu principal produto é uma carteira escolar com um sistema "thin-client" integrado. Não se diferencia formalmente do mobiliário escolar tradicional, exceto pela tela e o teclado embutidos na mesa. Os principais pontos positivos descritos pela empresa são as vantagens do sistema "thin-client" (que são, portanto, inerentes a qualquer um que utilize o mesmo sistema) e a resistência ao vandalismo.

Os teclados resistentes a impactos ficam embutidos na mesa e os monitores são protegidos por vidros, com acesso bloqueado com tranca e chave. Segundo a própria empresa, a Carteira Informatizada já foi instalada em pelo menos 600 salas de aula, em cidades como Camaçari (BA), Barueri e Hortolândia (SP), Cideira (RS), Florianópolis (SC), entre outras. No entanto, assim como a carteira Lap Tup-niquim, a Cadeira Informatizada da Oppitz também mantém a estrutura fixa tradicional nas salas de aula. Dessa maneira, a inclusão da informática na sala de aula é feita de forma incompleta, já que o dinamismo presente em seu universo da comunicação em rede não é traduzido para a estrutura física do ambiente.

Nas pesquisas realizadas durante a etapa de confecção da Revoluti restou evidenciado que nenhum desses projetos nacionais dá atenção aos novos modelos de Educação e de Comunicação que a sua introdução no cotidiano escolar exige,. inclusive devido à limitações que esses modelos compartilham que foram superados na Revoluti, em especial o fato da interação real e virtual ser uma preocupação resolvida apenas em nosso modelo.

Tal situação não é diferente do que encontra-se nos modelos mais avançados no cenário internacional, identificadas durante as pesquisas realizadas. Entre elas merecem atenção especial o OLPC, a sala do futuro do MIT, além dos projetos realizados a partir da pesquise do Design Council e do Ministério da Educação do Reino Unido. 
A OLPC - One Laptop Per Child (http://laptop.org/en) - é uma ONG que gerencia o projeto de distribuição do laptop $\mathrm{XO}$ para escolas públicas em países em desenvolvimento. Os países associados ao projeto se comprometem com os 5 princípios centrais do projeto: os laptops devem pertencer às crianças, o foco principal é nas crianças entre 6 e 12 anos de idade, todas as crianças de uma escola devem ganhar o notebook simultaneamente, os computadores tem que estar conectados à internet, e o software utilizado deve ser gratuito e aberto, de maneira que as próprias crianças possam desenvolver, adaptar e melhorar os programas já existentes.

O XO é um laptop que foi projetado especificamente para o uso por crianças em locais com poucos recursos. Seus componentes utilizam pouca energia para otimizar o uso da bateria, que pode, inclusive, ser recarregada a partir de uma manivela. O computador funciona criando uma rede com outros computadores semelhantes, de maneira que mesmo havendo apenas um ponto de distribuição em uma determinada região, os próprios computadores servem como distribuidores dessa conexão. No Brasil, o XO é considerado uma das opções para o programa UCA - Um Computador por Aluno, no entanto existem outras soluções que concorrem por preço com o XO.

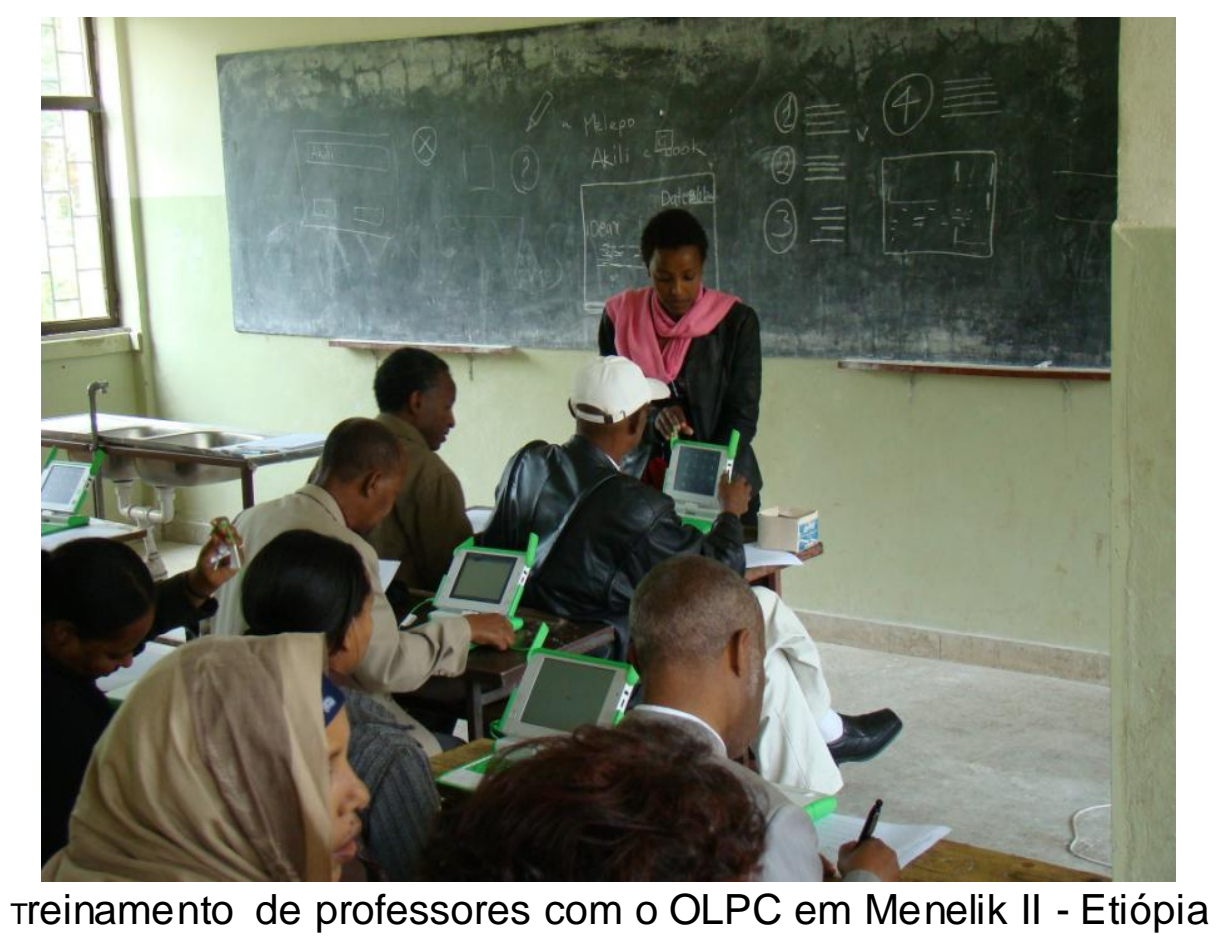


Apesar da grande mudança que a distribuição do laptop gera para o estudante, não existem muitas mudanças significativas na estrutura da sala de aula, que permanece dividida em fileiras. Além disso, o fato do computador pertencer ao estudante o deixa sujeito à acidentes domésticos, ou descarga na bateria, por esquecimento, por exemplo, o que pode atrapalhar a dinâmica da aula.

Uma outra proposta interessante para a educação do futuro é a sala de aula modelo do MIT, o Instituto de Tecnologia de Massachusetts, que permite primordialmente 0 trabalho em equipe. A sala é composta por mesas redondas para grupos de até 9 alunos, e nela podem ser realizadas uma série de atividades. Cada mesa possui pelo menos três laptops, e nas paredes próximas às mesas existem telões conectados aos laptops para que um grupo possa compartilhar seu trabalho com o resto da turma. Nesse modelo o mesmo grupo trabalha junto durante um semestre, - que favorece a aproximação entre os componentes do grupo e, consequentemente, melhora o seu rendimento durante o desenvolvimento dos trabalhos. A sala, no entanto, não possui muita flexibilidade, uma vez que não oferece a possibilidade da formação de outros tipos de grupo ou da realização de outros modelos de aula.

O terceiro projeto observado é resultado da pesquisa do Design Council (2002-a e 2002-b)e do Ministério de Educação, ambos do Reino Unido. O foco da pesquisa inicial foi a sala de aula como ambiente de formação de conhecimento, e a conclusão à que chegaram foi muito parecida com o que é consenso nas pesquisas sobre sala de aula do futuro: as salas atuais não são estimulantes, limitam os estilos de aula, o distanciamento do professor e do aluno não contribui para a interação, a estrutura em fileiras e colunas também não favorece a interação entre os alunos. A partir destas e de outras constatações, dois projetos foram propostos com o objetivo de melhorar o espaço da sala de aula.

Um dos projetos era composto por uma mesa de uso em duas posições com cadeira integrada. A mesa poderia ser usada para fazer anotações ou como encosto para a cadeira, quando os alunos estariam discutindo algum tema. $O$ segundo projeto também possui uma cadeira integrada à mesa, no entanto a cadeira girava ao redor da mesa e ao redor dela própria, possibilitando que os alunos trabalhem nas mesas de outros alunos que estejam próximos. Nos dois casos aumenta-se a interação 
entre os alunos, no entanto eles não consideram a inclusão do computador e suas características de rede na sala de aula.

Em suma, há em todo o mundo investimentos na pesquisa a respeito de mudanças fundamentais na estrutura física e nos equipamentos de sala de aula. Há também um conjunto de esforços para a introdução da informática em rede como ferramenta essencial das atividades escolares. As pesquisas que realizamos, quando comparadas com esses outros esforços, parecem combinar de forma única esses esforços.

\section{6 - Os próximos passos e questões da pesquisa}

Em diversos momentos do estudo e desenvolvimento da Revolui nos indagamos a respeito da real necessidade de um mobiliário escolar novo que pudesse receber equipamento de informática. Esta pegunta foi fundamental, pois nos levou à concepção que apenas "uma mesa", por mais elegante que fosse a solução, seria insuficiente para resolver a contento o paradoxo que nos levou à pesquisa: a introdução de inovações no campo de informática em rede operar em sentido inverso das inovações das pedagogias ativas e interativas. Daí surgiram os primeiros desenhos de "mesas articuladas compondo um sistema de mesas articuladas" que resultaram no primeiro protótipo de Sala de Aula do Futuro Revoluti. O conceito de ambiente escolar em que todos os estudantes e professores disponham de seu próprio equipamento é uma evolução do debate a respeito de como transcender o "PC" em direção ao "Public Computer".

Esse conceito já se faz presente por meio de instalação de laboratórios escolares de informática ${ }^{8}$, mas é fonte de amplos debates, mesmo nos países cuja população possui elevado poder aquisitivo médio. Nos EUA, por exemplo, HAWKINS \& OBLINGER (2007) sugerem que embora aparentemente os estudantes de hoje possuam elevadas habilidades no uso das tecnologias de informação, nem todos possuem seus computadores pessoais e uma parcela considerável dos que os possuem não podem pagar pelos custos dos programas e das atualizações de equipamento. Portanto, a existência de laboratórios públicos de informática nos campus de educação superior ainda é um dos principais itens para a igualdade de

$8 \quad$ O uso público de sistemas de informática em rede já está consagrado também em bibliotecas públicas e na oferta (pública ou privada) denominadas como cybercafes ou lan houses. 
oportunidades educacionais. Para os autores, esses laboratórios são fundamentais como "ambientes de socialização" a ponto de serem favoráveis à sua utilização, fora dos horários de atividade educacional, para entretenimento.

Um outro exemplo é recente pesquisa realizada no Brasil (FUNDAÇÃO VICTOR CIVITA, 2009) em quatrocentos escolas de Ensino Fundamental e Médio revelou que esse equipamento se faz presente nas atividades de administração e em laboratórios de informática, mas, embora a maioria delas possua recursos suficientes para uso pedagógico do computador e da internet, não foi verificado nenhum exemplo de utilização de tecnologia para o ensino e aprendizagem de um conteúdo específico que mereça destaque. Entre os principais motivos apresentados pelos respondentes que explicaria a conclusão anterior estão o pequeno número de profesores que utilizam a tecnologia em suas aulas (com exceção das escolas em que há Professores Orientadores de Informática) e a falta preparo dos docentes para o uso da tecnologia focado na aprendizagem de conteúdos e no desenvolvimento de competências e habilidades dos alunos.

Mas se estes laboratórios já estão plenamente justificados e em processo de disseminação - a ponto de não ser mais utopia e já começar a evidenciar uma série de problemas e de obstáculos - ainda nos parecem uma forma insuficiente de aplicação da informática no processo de ensino. A pesquisa que resultou na Revoluti partiu da perspectiva de aplicação do conceito de "public computers" seja utilizado no cotidiano da sala de aula.

Nos dois exemplos citados encontramos justificativas para as pesquisas que realizamos, bem como os parâmetros para sua a continuação:

- as inovações no campo da informática em rede (equipamentos, programas, plataformas etc) ainda são distribuídos de forma extremamente desigual, mesmo nos países mais desenvolvidos, se a categoria "exclusão digital" perdeu o seu valor absoluto, ela ainda se faz presente de forma relativa, em especial pela capacidade diferencial de interação via upload;

- as competências, habilidades, perspectivas e desejos dos estudantes nesse campo - inclusive entre os que não possuem seus próprios equipamentos - são mais desenvolvidas do que a de seus professores, sendo que um dos motivos para isso é que os professores possuem menos tempo de contato cotidiano com essas 
inovações. Essa distância tende a aumentar caso elas não sejam introduzidas como uma nova cultura e um novo cotidiano nas salas de aula;

- a capacitação do corpo docente no campo da informática em rede tende a apresentar poucos efeitos caso as atividades que eles realizarão sejam eventuais. $O$ desenvolvimento desse campo já ultrapassou o nível do "plug and play" em relação aos equipamentos e seus periféricos e os programas e plataformas existentes são auto-explicativos sendo que o desenvolvimento de habilidades para a sua utilização dependem mais de contato cotidiano do que de cursos preparatórios;

- os modelos de introdução da informática em rede na aula cotidiana precisam levar em consideração tanto a redução dos custos de atualização dos equipamentos o de geração de lixo tecnológico (seja por dano, seja por obsolescência);

- os programas educativos existentes são, em sua maioria, desenvolvidos para aprendizagem individual, sendo necessária a pesquisa sobre programas de aprendizagem interativa, provavelmente com fundamento nas redes sociais, via blogs e outras formas de hipertexto, inclusive chat-roons (salas de bate-papo), gravação da atividade de ensino em áudio e em vídeo bem como a transcrição em texto dos diálogos travados para posterior acesso, além de tratar de temas complexos como o "letramento com mediação tecnológica" (superação do letramento com mediação do lapis e papel) e do ensino de matemática por meio de calculadoras virtuais.

Essas cinco diretrizes serão investigadas na atual Sala Protótipo Revoluti e nas outras quatro que serão instaladas na UERJ com o fomento da FAPERJ ${ }^{9}$. Uma das características da informática em rede e das tecnologias de inovação é que o seu uso constante e por um grande número de pessoas acelera o potencial de seu desenvolvimento. Nessa pesquisa também serão avaliados aspectos tradicionais da pesquisa sobre "sala de aula", a saber, a atenção e a motivação dos participantes, o tempo utilizado para as atividades, as competências e habilidades educativas adquiridas (qualidade e rendimento), os esquemas de socialização etc. Daremos atenção especial ao "efeito colateral" da Sala Revoluti no material escolar dos estudantes, pois a sua implantação significa que para eles bastará comparecer às aulas com um dispositivo de gravação de arquivos digitais. Entre os professores 
será avaliado também o efeito, em seu trabalho, da dispensa do "quadro negro", tendo em vista que cada estação de trabalho, seja a dos alunos, seja a do professor, se configurará como um "smart board".

Uma das principais percepções durante o nosso processo de pesquisa foi que a promessa utópica da informática em rede e das tecnologias de inovação alterarem de forma capital as relações humanas de ensino e de aprendizagem está em vias de se realizar. Seja pelo modelo OLPC, seja pela Revoluti, seja por qualquer outro sistema estão próximos os tempos em que cada professor e cada estudante se dirigirá para as escolas munido apenas com um dispositivo digital. A Sala Revoluti se apresenta como uma das possibilidades desse futuro promissor, misterioso e assustador, mas inevitável e necessário.

\section{6 - Bibliografia}

BLIKSTEIN, P. \& ZUFFO, M. K. As sereias do ensino eletrônico. http://www.blikstein.com/paulo/documents/books/BliksteinZuffo-MermaidsOfEteaching-OnlineEducation.pdf, acessado em 21/04/2009.

ERENO, D. Carteiras informatizadas. Mesas reúnem tela sensível ao toque para a escrita manual e computador Revista da FAPES. Edição Impressa 147 - Maio 2008 in http://www.revistapesquisa.fapesp.br/?art=3524\&bd=1\&pg=1\&lg.

CRONEMBERGER, E; Lage, D \& GUIGON, G. Habto design. (projeto de fomento) Rio de Janeiro: Fundação Bio Rio, 2009.

CRONEMBERGER, E; Lage, D; GUIGON, G. \& SOBREIRA, H. G. Mesas Articuladas e Sistemas de Mesas Articuladas. (Patente Requerida, Invenção). Rio de Janeiro: Habto Design \& FEBF, 2009.

de Kerckhove, D. A Pele da Cultura (Uma investigação sobre a nova realidade eletrônica). Lisboa: Relógio D'Água Editores, março de 1997.

DESIGN COUNCIL, The Furniture Debate. Londres, 2002 (www.century21schools.com)

DESIGN COUNCIL, Learning Environments Campaign Prospectus From the Inside Looking Out. Londres, Design Coucil, 2002-b

FUNDAÇÃO VICTOR CIVITA. O uso dos computadores e da internet nas escolas públicas de capitais brasileiras. São Paulo: Fundação Victor Civita, 2009 (disponível em http://revistaescola.abril.com.br/fvc/pdf/estudo-computadorinternet.pdf) 
G1. Proibido uso de celulares nas escolas públicas estaduais. http://g1.globo.com/Noticias/Rio/0,MUL400760-5606,00.html, acessado em $21 / 04 / 2009$

HAWKINS, B. L. \& OBLINGER, D. G. The Myth about the Need for Public Computer Labs. In EDUCAUSE Review, vol. 42, no. 5 (September/October 2007): 1011.

(http://www.educause.edu/EDUCAUSE+Review/EDUCAUSEReviewMagazine Volume42/TheMythabouttheNeedforPublicCo/161912, acesso em outubro de 2009)

LIMA, L. F. G. Subjetividade e novas tecnologias: um estudo da mediação tecnológica, de telefones celulares, na interação de jovens. Fortaleza: Universidade Federal do Ceará (Dissertação de Mestrado), 2006.

MONTEIRO, C. F. Celular na sala de aula como alternativa pedagógica no cotidiano das escolas. http://www.anped.org.br/reunioes/29ra/trabalhos/trabalho/GT16-2668-Int.pdf, acessado em 21/04/2009.

OOPTIZ. O que é a Carteira Informatizada OPPITZ ? in http://www.oppitz.com.br/index.php/produtos/carteira-informatizada. 2009.

SOBREIRA, H. G. Modelos de Educação e de Comunicação para as Salas de Aula do Futuro. (Projeto de Pesquisa). Rio de Janeiro: FAPERJ, 2009. 